\title{
Meeting Update: International Society for Heart and Lung Transplantation 2014
}

\author{
David A. Baran, Jaime A. Hernandez-Montfort, Pavittarpaul Dhesi \\ Heart Failure and Transplant Research, Newark Beth Israel Medical Center, New Jersey, USA
}

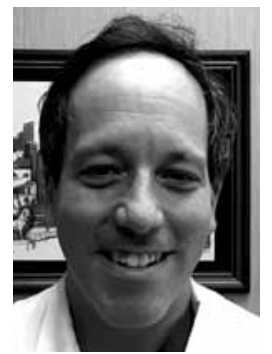

Kardiochirurgia i Torakochirurgia Polska 2015; 12 (1): 37-41

The $34^{\text {th }}$ annual meeting of the International Society for Heart and Lung Transplantation was convened in San Diego, California, USA on April 10-13, 2014. It was one of the best attended meetings ever with more than 3,000 attendees and the enthusiasm and excitement was palpable in the Manchester Grand Hotel where the meeting was held. This paper will describe a few of the most important contributions from this meeting, recognizing that with so many papers, it is certain that many worthwhile manuscripts will go unmentioned. The topics that will be highlighted are heart transplant trials, non-invasive detection of allograft rejection and vasculopathy, as well as mechanical circulatory support and extracorporeal membrane oxygenation (ECMO).

\section{Heart transplant trials}

Ardehali presented the results of the PROCEED II Trial [1]. This was an international, randomized non-inferiority trial to assess the clinical efficacy and safety of the Organ Care System (OCS device). The investigators compared OCS technology which keeps the heart beating in a normothermic fashion to cold storage prior to transplantation. A total of 128 heart transplant recipients were enrolled in the trial. There were no differences between the OCS and ice preservation groups in reference to incidences of cardiac adverse events, rejection and time spent in the ICU. The Proceed II trial also met the primary effectiveness and safety endpoints and success criteria for the Unites States Food and Drug Administration approval process. This is a very exciting trial as it sets the stage for further studies looking at the use of marginal donor hearts or standard criteria hearts which would require long travel times that render then unusable with the conventional ice preservation method.

There were several abstracts on the outcomes of the SCHEDULE trial [2-6]. This was a prospective, randomized multicenter 12-month Scandinavian trial where 115 de novo heart transplant recipients were randomized to everolimus with complete calcineurin inhibitor (CNI) withdrawal (EVE-group) 7-11 weeks after heart transplantation or stan- dard CNI-based immunosuppression (CNI group). Ninetyfive (83\%) patients had matched intravascular ultrasound examinations (IVUS) at baseline and 12 months and were analyzed to measure change in maximal intimal thickness (MIT). Mean recipient age was $49.9 \pm 13.1$ years. The EVE group $(n=47)$ demonstrated significantly reduced cardiac allograft vasculopathy progression as compared to $\mathrm{CNI}$ $(n=48)$. The change in MIT was $0.03 \pm 0.06 \mathrm{~mm}$ in the EVE group and $0.08 \pm 0.12 \mathrm{~mm}$ in the CNI group $(p<0.01)$.

The patients in the SCHEDULE trial who received everolimus had improved GFR over time compared to a minor reduction of estimated GFR in the CNI group [5]. The degree of microalbuminuria was higher in the everolimus group as well which was of uncertain clinical significance. The role of everolimus remains uncertain due to toxicities but trials such as SCHEDULE add to our understanding of the benefits of this therapy.

\section{Non-invasive diagnosis of allograft rejection and vasculopathy}

Current monitoring of post heart transplant patients is a topic of debate. In 2010, the International Society of Heart and Lung Transplantation (ISHLT) published guidelines for the care of heart transplant recipients. Given the paucity of clinical trials in such an exclusive group of patients, many of the recommendations were patient on consensus of a panel of experts.

The current guidelines recommend that adult heart transplant (HT) patients undergo periodic endomyocardial biopsies (EMB) during the first 6-12 months after HT (Class Ila, Level of Evidence: C). After the first post-operative year, EMB surveillance for an extended period of time (every 4-6 months) after HT who are at higher risk for late acute rejection (Class Ila, Level of Evidence: C) [7]. The ISHLT guidelines do not recommend an exact surveillance schedule and defer the particular decision making to each transplant center.

While EMB is considered current gold standard to rule out rejection, it is not without risk. Given the invasive na- 
ture of the procedure and its associated patient discomfort and risk profile, many have called into question whether EMB should be scheduled routinely or purely event driven. The IMAGE study group showed that a recipient's gene expression provides valuable information about the risk of acute cellular rejection (ACR) [8]. Given the fact Gene expression profiling (Allomap, CareDx Inc, Brisbane, CA) was considered non-inferior to $E M B$, the guidelines state that it can be used to rule out the presence of $A C R$ of grade $2 R$ or greater in low risk patients between 6 months and 5 years after HT [7]. Furthermore, additional work by the IMAGE group has shown that gene expression profiling store variability in cardiac allograft recipients is independently associated with future clinical events (rejection with hemodynamic compromise, graft dysfunction due to other causes, death, or retransplantation) [9].

Gene expression profiling remains limited in that it is approved only to detect rejection that requires treatment and can often be cost-limiting in its application. Recent work has shown the potential for stirring up competition in the market by using whole blood tests to monitor rejection. A Canadian study by Hollander et al. detailed the early development of a proprietary quantitative nuclease protection assay microarray (utilizing a total of 40 genes) that shows potential for detecting ACR. The researchers found that a modified panel focusing on 10 genes showed $100 \%$ sensitivity and $74 \%$ specificity (100\% negative predictive value and $14 \%$ positive predictive value) when detecting reduction [10]. The assay needs to be tested clinically for reproducibility but there is potential for such a test to be performed in the future in lieu of routine EMB or gene expression profiling.

Aside from the above-mentioned gene expression profiling, non-invasive methods of evaluation post cardiac transplant patients are limited. Currently, the guidelines frown on the use of imaging modalities, including echocardiography and magnetic resonance imaging (MRI), for allograft rejection monitoring in adult recipients given the lack of evidence to support their use [7]. Two recent studies, however, have demonstrated the potential role of two-dimensional speckle-tracking echocardiography to evaluate cardiac allograft rejection. Sera et al. evaluated 160 EMBs from 59 asymptomatic patients and showed that lower left ventricular global longitudinal strain (GLS) was significantly associated with an increased risk of treatment-requiring rejection (ISHLT grade 2R) [11]. Similarly, Clemmensen et al. recently presented data on 585 EMBs performed in 64 patients and showed similarly significantly lower GLS scores in grade $2 \mathrm{R}$ rejection even in patients with a normal left ventricular ejection fraction and those without CAV [12].

To rule out cardiac allograft vasculopathy (CAV), the current ISHLT guidelines recommend annual or biannual angiography to assess for its development. Patients free of CAV at 3 to 5 years can undergo less frequent surveillance (Class I, Level of Evidence: C). Similarly, intravascular ultrasound (IVUS) in conjunction with angiography is recommended at 4-6 weeks and at 1 year after HT to rule out donor coronary artery disease (CAD) and detect rapidly progressive CAV. While angiography is performed less frequently than EMB, it too carries a risk profile with the possibility of serious adverse effects. Toma et al. recently discovered a proprietary panel with 7 proteins that were able to identify patients with an absence of significant left anterior descending artery (LAD) occlusion (lumen diameter reduction less than $20 \%$ ) with a negative predictive value of $92 \%$. While the study had its limitations, including application to only 24 patients (3 with CAV and 21 without) and its assessment of only LAD lesions, it warrants further evaluation of its reproducibility [13].

While a paradigm shift in the near future is unlikely, significant developments in non-invasive identification of cardiac allograft rejection and CAV are ongoing. After further testing and demonstration of clinical reproducibility, there remains potential that heart transplant recipients may eventually undergo routine rejection surveillance via a combination of echocardiographic and blood testing.

\section{Mechanical circulatory support and extracorporeal membrane oxygenation \\ Continuous flow left ventricular assist devices and valvular heart disease}

Several contributions offered important insights related to the interaction of valvular heart disease and continuous flow left ventricular assist devices (CF-LVADs). Despite bases derived from observational studies, important associations were noted particularly with findings related to distinct valvular pathology and their treatment implications at different stages in patients with CF-LVADs. Robertson et al. evaluated concomitant aortic valve procedures in patients with aortic insufficiency undergoing implantation of continuous flow LVADs entered into the INTERMACS database between 2006 to 2012. Survival was reduced significantly for AV closure (63\%) compared to AV repair $(73 \%)$ and replacement $(74 \%, p<0.001)$ and after multivariate adjustment, aortic valve closure remained a significant risk factor for mortality $(\mathrm{HR}=1.95,95 \% \mathrm{Cl}$ : 1.45-2.62, $p<0.0001$ ). Competing outcomes at 1-year showed similar percentages of patients transplanted irrespective of the presence/absence of an aortic valve procedure and there were no differences between the groups in respect to cause of death, re-hospitalization, right heart failure or stroke [14]. In regards to mitral valve disease, Maltais et al. evaluated the impact of mitral regurgitation on survival and continuous flow LVAD-related complications at three institutions, dividing patients into two groups - severe MR (MR) and less than severe MR (lessMR) [15]. There was a survival benefit in patients with severe preoperative MR. Survival was preserved in patients with $M R$ and concomitant severe tricuspid regurgitation (TR) and was worse in patients with lessMR and TR. Severe preoperative MR had no effect on LVAD related complications (hemolysis, pump thrombosis, stroke and gastroin- 
testinal bleeding). These findings suggest that mitral valve surgery at the time of LVAD implantation for severe $M R$ is perhaps a clinical question that merits further investigation [15]. Song and others attempted to determine the impact of tricuspid valve repair (TVR) at the time of LVAD implantation for destination therapy on survival, utilizing the INTERMACS registry [16]. Among 2477 patients undergoing C-LVAD for DT since 2006, 322 (13\%) had TVR. There was varied utilization of TVR among experienced centers (0-55\%) and multivariate analysis identified the following pre-implant risk factors for reduced survival: advanced age, higher BMI, creatinine, BUN, bilirubin and right atrial pressure; INTERMACS level 1 and 2; mechanical ventilation, prior CABG; implant of an RVAD and moderate or severe tricuspid regurgitation. Tricuspid valve repair was not associated with improved survival even in patients with preimplant moderate or severe TR. Patients with pre-implant moderate to severe TR who underwent LVAD implant with concomitant TVR had a relatively higher incidence of later TR but lower than those who underwent LVAD implant alone [16]. Aside of concomitant valvular interventions on LVAD recipients, an important area of controversy has been the importance of pulsatility and aortic valve opening in patients with CF-LVADs. Taking a step back and addressing the clinical day to day practice, Bhimeraj and others studied the interaction between pulse perception, blood pressure and visual assessment of aortic valve opening in patients with C-LVADs in the outpatient setting [17]. Aortic valve opening using a handheld echocardiogram was evaluated within a few minutes of the heart failure cardiologists and VAD coordinators assessment of radial pulse. There was a concordance in the assessment of pulse between $M D$ and RN irrespective of status of AV opening (40\% of patients with no AV opening perceived to have a pulse and $20 \%$ with AV opening did not have a pulse). These findings redefine the clinical assessment of pulsatility beyond the simplicity of the absence or presence of a pulse [17].

\section{RAMP echo and continuous flow left ventricular assist devices}

Routine echocardiographic surveillance of CF-LVADs has become a standard of care in the majority of advanced heart failure centers, thus is important to highlight the contributions related its hemodynamic interpretation across distinct devices. Uriel and others tested the ramp protocol on 15 patients with HVAD prior to discharge or at the time of suspected device malfunction with the following echo parameters such as left ventricular end-diastolic dimension (LVEDD), frequency of aortic valve opening and valvular insufficiency recorded within two-minute increments of 100 rpms from 2,300 to 3,200 rpm [18]. There was a nonlinear relationship between device speed and LVEDD observed in patients with normally functioning LVAD with the device flow rapidly increasing prior to AV closure and flattening of the mean slope after it [18]. Jung et al. evaluated the pressure-volume relationship in patients supported with continuous flow LVAD comparing simultaneous echocardiogram RAMP testing (usual pump setting; ramp-base, then at 8000 RPM; ramp-low, increasing by 400 RPM/5 minutes until reaching 12,000 RPM or suction/arrhythmic event; ramp high) with simultaneous measurement of PCWP [19]. In nine patients with CF-LVAD (HM II), the correlation between PCWP (ramp-low: $19 \pm 4$, ramp-base: $14 \pm 4$, ramp-high: $6 \pm 2 \mathrm{mmHg}$ ) and LVEDD (ramp-low: $64 \pm 10$, ramp-base: $66 \pm 9$, ramp-high: $52 \pm 16$ $\mathrm{mmHg}$ ) was non-significant [19].

\section{Continuous flow left ventricular assist devices and neurologic events}

There were important contributions in which results highlighted the relationship between of blood pressure control and neurologic events in patients with CF-LVADs. Teuteberg et al. reviewed the incidence of neurologic events (ischemic [I] and hemorrhagic [H] CVA) after implantation of HVAD, LVAD as BTT and continuous access protocol on 382 patients followed through 2013. The overall incidence of ICVA was $5.2 \%$ and HCVA $8.4 \%$. Established protocols for intensive blood pressure management (IBPM) were implemented in 8 out of the 30 participating sites and despite similar rates of ICVA in those with and without IBPM (5.3\% vs. $5.2 \%)$, the rates of HCVA with IBPM were significantly lower $-2.6 \%$ vs. $10.8 \%$ ( $p$ < 0.0007). Multivariate predictors of ICVA were aspirin < $81 \mathrm{mg}$, age > 56 and mean arterial pressure $(M A P)>90$; for HCVA were MAP > 90, ASA < $81 \mathrm{mg}$, INR $<2$ or $>3$ and diabetes [20]. Similar findings associating elevated blood pressure with $\mathrm{ICH}$ were presented in a single center retrospective study by Saeed et al. of 106 patients supported between day 30 and year 1 (2006-2013) with HM II. High DBP (> $90 \mathrm{mmHg}$ ) was associated with a greater risk of $\mathrm{ICH}$ in comparison to lower DBP (hazard ratio $7.0 ; 95 \% \mathrm{Cl}: 1.4-11.9 ; p=0.02)$ [21].

\section{Continuous flow left ventricular assist devices and bleeding}

The UTAH bleeding risk score model was developed by Weber-Pinzon and colleagues as an attempt to predict the risk of non-surgical bleeding among patients receiving CF-LVADs, utilizing pre-implantation variables independently associated with major bleeding which was defined as a decrease in hemoglobin $>2 \mathrm{~g} / \mathrm{dL}$ in the absence of hemolysis. The total number of patients was 201, with a median age of 60 years old and after 150-day medial follow-up, major bleeding occurred in $33 \%$ of the patients: $78 \%$ gastrointestinal, $10 \%$ epistaxis, $9 \%$ intracraneal and $3 \%$ "other". Seven independent predictors of major bleeding were included in the model: age > 54 years, history of bleeding, serum fasting glucose $>104 \mathrm{~g} / \mathrm{dl}$, hemoglobin $<12 \mathrm{~g} / \mathrm{dl}$, creatinine $1.5 \mathrm{mg} / \mathrm{dl}$, in addition to mild/moderate and severe right ventricular dysfunction on echocardiography. The six-month survival free from bleeding in the low, medium and high-risk group was $95 \%, 70 \%$ and $16 \%$, respectively $(p<0.0001)$ with good discrimination in the development sample (C-index 0.76) and after internal validation (C-index 0.71) [22]. 


\section{Advanced heart failure and continuous flow left ventricular assist devices hemodynamics}

Several studies showing the application of novel hemodynamic indices in patients with advanced heart disease are worthwhile noting. Grodin et al. evaluated the prognostic role of cardiac power indices (CPI) in an advanced chronic heart failure population via invasive hemodynamic, echocardiographic and exercise stress testing assessment of 495 patients. Patients with low CPI had lower MAP, higher right atrial pressures (RAP), higher pulmonary capillary wedge pressure (PCWP), lower eGFR, higher BNP, lower LVEF, and higher LV end diastolic diameter $(p<0.0001$ for all). Lower CPI provided significant independent prediction of a 3.6-fold increase in the mortality risk and $\mathrm{OHT}$ (HR 3.64 [2.57-5.24], $p<0.0001$ ). In patients with low peak $\mathrm{VO}_{2}$, lower CPI provided independent prediction of a 2.6fold increase in the mortality risk and OHT (low CPI vs. high CPI: 2.57 [1.46-4.71], $p=0.0009$ ) [23]. The prognostic utility of pulmonary artery pulsatility index (PAPi) defined as (systolic pulmonary artery pressure - diastolic pulmonary pressure)/central venous pressure was evaluated by Kang and Banerjee in an effort to predict right ventricular failure (as defined by INTERMACS) after LVAD implantation. A cohort of 80 patients undergoing CF-LVAD implantation was analyzed over a 3-year period. Right ventricular failure occurred in $33 \%$ of patients with $11 \%$ requiring a right ventricular assist device (RVAD). In univariate models a 1 unit increase in PAPi was associated with RVAD placement (OR 2.1, 95\% Cl: 1.03-4.4) and clinical RVF (OR 1.7, 95\% Cl: 1.15-2.5). When stratified by the use of inotropes at the time of right heart catheterization, PAPi was more predictive of RVAD use when inotropes were used at the time of RHC (OR 3.0, 95\% Cl: 0.8-11.7) than RHC without inotrope use (OR 1.9, 95\% Cl: 0.6-6.0) [24].

\section{Percutaneous MCS as a bridge to decision in cardiogenic shock}

There were multiple contributions associated with the role of percutaneous mechanical circulatory support as a bridge to decision in patients with critical cardiogenic shock. Takayama et al. summarized the most recent results of the study group consortium registry RESCUE (Registry for Cardiogenic Shock: Utility and Efficacy of Device Therapy) which is the first of its kind dedicated to patients that received mechanical circulatory support device for cardiogenic shock. Of the 228 patients that received MCS between 2012 and 2013 the indications included acute myocardial infarction (30.3\%), postcardiotomy shock (26.3\%), acute decompensating heart failure (15.8\%), and graft failure post heart transplantation (9.2\%). Venoarterial ECMO was used in $82.7 \%$ and short term VAD in $18 \%$. Mean age was 58.5 years and overall duration of support was $7.3 \pm 7.4$ days. Overall the survival to hospital discharge was $55 \%$ and $47 \%$ of patients achieved myocardial recovery allowing device implantation, however there was a wide difference of survival among institutions (43.5\% to 68.2\%) [25]. Balasubramanya et al. described a single center experience with ECMO as a bridge to recovery, bridge to VAD and bridge to OHT between 2010 and 2012. The overall survival of all ECMO patients was $32.8 \%$ (20/61). The survival of patients that were bridged to VAD was $62.5 \%$ and of those who underwent heart transplantation was $100 \%$ [26]. Moriguchi et al. described their experience with INTERMACS 1 patients who presented in cardiogenic shock and were placed on ECMO as emergent (bridge to decision) BTD support. The median time was 5.5 days with a range of 1 to 35 days. Of the 40 patients reviewed, 19 expired on ECMO, 5 were placed on total artificial heart and 9 on other mechanical circulatory support devices, 1 patient was transplanted, 5 patients recovered and 1 patient received palliative care [27]. Landes et al. evaluated the circulatory support provided by the use of partial flow with $15 \mathrm{~F}$ arterial cannula in VA-ECMO. The partial and full flow cohort's hemodynamic and metabolic status was evaluated at $24 \mathrm{hrs}$. of support. The ECMO flow in the full flow was higher (average flow $2.1[ \pm 0.5] \mathrm{l} / \mathrm{m}^{2}$ / $\mathrm{min})$ than in the partial flow group $\left(1.7[ \pm 0.3] \mathrm{l} / \mathrm{m}^{2} / \mathrm{min}\right)$, however there was no significant difference in vasopressor and inotrope use, or in hemodynamic or laboratory variables, there was no difference in 30-day survival. Bleeding complications were more frequent in full-flow (47\%) compared to the partial-flow group (26\%) with no significant difference in the occurrence of CVA or LV distention [28].

\section{Conclusions}

With nearly 1000 abstracts, and a worldwide slate of attendees, the ISHLT 2014 meeting was one of the most intensive and interesting annual gatherings to date. The authors have recounted some of the most interesting findings and we look forward to full-length manuscripts forthcoming on many of these critical areas of investigation. We can hardly wait until next year when the ISHLT travels to Nice, France!

\section{Disclosure}

Authors report no conflict of interest.

\section{References}

1. Ardehali A, Esmailian F, Deng M, Soltesz E, Hsich E, Naka Y, Mancini D, Camacho M, Baran D, Zucker M, Leprince P, Madsen J, Tsui S, Simon A, Livi U, Guzzi G, Kobashigawa J. The Proceed II International Heart Transplant Trial with the Organ Care System (OCS ${ }^{\text {TM}}$ ) Technology. J Heart Lung Transplant 2014; 33 (4 Suppl): S118.

2. Arora S, Andersson B, Gustafsson F, Eiskjćr H, Rådegran G, Aaberge L, Erikstad I, Gude E, Ueland T, Aukrust P, Solbu D, Dellgren G, Andreassen A, Gullestad L. Everolimus Initiation With Calcineurin Inhibitor Withdrawal Reduces Allograft Vasculopathy in De-Novo Heart Transplant Recipients. J Heart Lung Transplant 2014; 33 (4 Suppl): S154.

3. Bartfay S, Gullestad L, Sigurdardottir V, Andreassen AK, Gude E, Andersson B. Maintained Cardiac Reserve in Heart Transplant Patients During Early Calcineurin Inhibitor Avoidance: A Substudy of a Randomised Controlled Trial (SCHEDULE Trial). J Heart Lung Transplant 2014; 33 (4 Suppl): S173-S174.

4. Gude E, Bartfay S, Andersson B, Sigurdardottir V, Stueflotten W, Gullestad L, Andreassen A. Exercise Capacity in De-Novo Heart Transplant Recipents With Everolimus Vs Conventional CNI Based Immunosuppresion. The Re- 
sults of a Randomized Trial (SCHEDULE). J Heart Lung Transplant 2014; 33 (4 Suppl): S134

5. Gustafsson F, Andreassen A, Arora S, Andersson A, Gude E, Eiskjćr H, Raadegran G, Dellgren G, Gullestad L. A CNI-Free, Everolimus Based Regimen in De-Novo Heart Transplant Recipients Increases Albuminuria But Improves Glomerular Filtration Rate Compared With Conventional Immunosuppression. J Heart Lung Transplant 2014; 33 (4 Suppl): S281.

6. Relbo A, Grov I, Andersson B, Gustafsson F, Eiskjćr H, Rådegran G, Gude E, Jansson K, Solbu D, Sigurdardottir V, Arora S, Dellgren G, Andreassen AK, Gullestad L. Everolimus and Cyclosporine Equally Improve QoL in De Novo Heart Transplanted Patients: The Results of a Randomized Controlled Trial (SCHEDULE Trial). J Heart Lung Transplant 2014; 33 (4 Suppl): S128.

7. Costanzo MR, Dipchand A, Starling R, Anderson A, Chan M, Desai S, Fedson S, Fisher P, Gonzales-Stawinski G, Martinelli L, McGiffin D, Smith J, Taylor D, Meiser B, Webber S, Baran D, Carboni M, Dengler T, Feldman D, Frigerio M, Kfoury A, Kim D, Kobashigawa J, Shullo M, Stehlik J, Teuteberg J, Uber P, Zuckermann A, Hunt S, Burch M, Bhat G, Canter C, Chinnock R, Crespo-Leiro M, Delgado R, Dobbels F, Grady K, Kao W, Lamour J, Parry G, Patel J, Pini D, Towbin J, Wolfel G, Delgado D, Eisen H, Goldberg L, Hosenpud J, Johnson M, Keogh A, Lewis C, O'Connell J, Rogers J, Ross H, Russell S, Vanhaecke J; International Society of Heart and Lung Transplantation Guidelines for the care of heart transplant recipients. J Heart Lung Transplant 2010; 29: 914-956.

8. Pham MX, Teuteberg JJ, Kfoury AG, Starling RC, Deng MC, Cappola TP, Kao A, Anderson AS, Cotts WG, Ewald GA, Baran DA, Bogaev RC, Elashoff B, Baron H, Yee J, Valantine HA; IMAGE Study Group. Gene-expression profiling for rejection surveillance after cardiac transplantation. N Engl J Med 2010; 362: 1890-1900.

9. Deng MC, Elashoff B, Pham MX, Teuteberg JJ, Kfoury AG, Starling RC, Cappola TP, Kao A, Anderson AS, Cotts WG, Ewald GA, Baran DA, Bogaev RC, Shahzad K, Hiller D, Yee J, Valantine HA; IMAGE Study Group. Utility of gene expression profiling score variability to predict clinical events in heart transplant recipients. Transplantation 2014; 97: 708-714.

10. Hollander Z, Lam KK, Wilson-McManus JE, Assadian S, Dai DL, Shannon C, Chen V, TebbuttSJ, Balshaw R, Borchers C, Davies RA, Delgado D, Haddad H, Ignaszewski A, Isaac DL, Kim DH, Mui A, Rajda M, Ross H, West LJ, White M, Zieroth S, McMaster RW, Keown PA, Ng RT, McManus BM. Blood Test to Monitor for the Absence of Acute Cardiac Rejection: From Discovery to Clinical Implementation. J Heart Lung Transplant 2014; 33 (4 Suppl): S26.

11. Sera F, Kato TS, Farr M, Russo C, Jin Z, Marboe CC, Di Tullio MR, Mancini D, Homma S. Left ventricular longitudinal strain by speckle-tracking echocardiography is associated with treatment-requiring cardiac allograft rejection. J Card Fail 2014; 20: 359-364.

12. Clemmensen TS, Løgstrup BB, Eiskjćr H, Poulsen SH. Changes in Longitudinal Myocardial Function During Acute Cardiac Rejection: The Clinical Role of 2D Speckle Tracking Echocardiography. J Heart Lung Transplant 2014; 33 (4 Suppl): S26.

13. Toma M, Hollander Z, Wilson-McManus JE, Lin D, Lam KK, Dai DL, Cohen Freue G, Tebbutt SJ, Balshaw R, Borchers C, Davies RA, Delgado D, Haddad H, Ignaszewski A, Isaac DL, Kim DH, Rajda M, Ross H, West LJ, White M, Zieroth S, Mancini JG, McMaster RW, Keown PA, Ng RT, McManus BM. Plasma Protein Biosignatures for Detection of Cardiac Allograft Vasculopathy. J Heart Lung Transplant 2014; 33 (4 Suppl): S25-S26.

14. Robertson JO, Meyers SL, Kirklin JK, Mertz GD, Prasad S, Itoh A, Silvestry SC. Concomitant Aortic Valve Procedures in Patients Undergoing Implantation of Continuous-Flow LVADs: An INTERMACS Database Analysis. J Heart Lung Transplant 2014; 33 (4 Suppl): S9.

15. Maltais S, Tchantchaleishvili V, Haglund NA, Cowger J, Davis ME, Keebler M, Joyce LD, Daly RC, Park SJ, Aaronson KD, Pagani FD, Stulak JM. Does Preoperative Mitral Regurgitation Influence Outcomes After Continuous-Flow Left Ventricular Assist Device Implantation? J Heart Lung Transplant 2014; 33 (4 Suppl): S34-S35.
16. Song HK, Mudd JO, Gelow JM, Chien CV, Tibayan FA, Hollifield KA, Naftel DC, Kirklin JK. Utility of Tricuspid Valve Repair at the Time of Left Ventricular Assist Device Implantation. J Heart Lung Transplant 2014; 33 (4 Suppl): S37-S38.

17. Bhimaraj A, Bellera RV, Martinez D, Cordero-Reyes AM, Elias B, Trachtenberg BH, Ashrith G, Torre-Amione G, Loebe M, Estep JD. Interaction of Pulse Perception, Blood Pressure Measurements (By Doppler and Standard Cuff Techniques) and Visual Assessment of Aortic Valve Opening in Continuous Flow LVAD Patients in the Outpatient Setting. J Heart Lung Transplant 2014; 33 (4 Suppl): S13-S14.

18. Uriel N, Levin AP, Mody KP, Dionizovik-Dimanovski M, Garan AR, Yuzefpolskaya M, Takayama H, Colombo PC, Naka Y, Jorde UP. Relationship Between Speed and Left Ventricular Size in HVAD Patients: Lessons from the HVAD Ramp Test Study. J Heart Lung Transplant 2014; 33 (4 Suppl): S12-S13.

19. Jung MH, Hassager C, Russell SD, Balling L, Rossing K, Boesgaard S, Gustafsson F. Pressure-Volume Relations in Patients Supported With ContinuousFlow Left Ventricular Assist Devices: A Comparative Descriptive Study of Invasive Hemodynamics Versus Echocardiography. J Heart Lung Transplant 2014; 33 (4 Suppl): S14.

20. Teuteberg JJ, Slaughter MS, Rogers J, McGee E, Pagani FD, Gordon R, Rame JE, Acker M, Kormos R, Salerno CT, Schleeter TP, Goldstein DJ, Shin J, Starling RC, Wozniak T, Malik AS, Silvestry SC, Ewald G, Birks EJ, Najarian KB, Hathaway DR, Aaronson KD. Impact of Device Design and Patient Management on the Incidence of Neurologic Events after HVAD Left Ventricular Assist Device. J Heart Lung Transplant 2014; 33 (4 Suppl): S10.

21. Saeed O, Jermyn R, Mannem S, Nucci C, Casazza D, Farooqui S, Bloom M, McLarty A, Zolty R, Shin J, Alessandro D, Goldstein DJ, Patel S. Intracranial Hemorrhage Is Associated with a Higher Doppler Blood Pressure during Continuous Flow Left Ventricular Assist Device Support. J Heart Lung Transplant 2014; 33 (4 Suppl): S24.

22. Wever-Pinzon J, Wever-Pinzon O, McKellar S, Badger C, Fang J, Drakos S, Gilbert E, Everitt M, Alharethi R, Budge D, Stehlik J, Kfoury A, Selzman C, Nativi-Nicolau J. A Novel Model to Predict the Risk of Non-Surgical Bleeding Among Patients Receiving Continuous Flow Left Ventricular Assist Devices. J Heart Lung Transplant 2014; 33 (4 Suppl): S22.

23. Grodin JL, Dupont M, Mullens W, Taylor DO, Starling RC, Tang W. The Prog nostic Role of Cardiac Power Indices in Advanced Chronic Heart Failure. J Heart Lung Transplant 2014; 33 (4 Suppl): S39.

24. Kang G, Banerjee D. Pulmonary Artery Pulsatility Index Predicts Right Ventricular Failure After LVAD Implantation. J Heart Lung Transplant 2014; 33 (4 Suppl): S86.

25. Takayama H, Kai M, Camacho M, Kalesan B, Jorde U, Truby L, Baran D, Zucker M, Sun B. Contemporary Outcome of Mechanical Circulatory Support Therapy: Analysis of Multicenter Registry, RESCUE. J Heart Lung Transplant 2014; 33 (4 Suppl): S37.

26. Balasubramanya S, Arabia F, Moriguchi J, Kobashigawa J, Esmailian F. Extracorporeal Membrane Oxygenation as a Bridge to Recovery, Bridge to Ventricular Assist Device and Bridge to Heart Transplantation: A Retrospective Review of Data From a Single Tertiary Care Institution. J Heart Lung Transplant 2014; 33 (4 Suppl): S78.

27. Moriguchi J, Arabia F, Jocson R, Patel J, Kittleson M, Liou F, Yu Z, Ernst W, Hamilton M, Chang DH, Czer L, Kobashigawa J. Extracorporeal Membrane Oxygenation as a Bridge to Decision for INTERMACS 1 Patients. J Heart Lung Transplant 2014; 33 (4 Suppl): S250-S251.

28. Landes EL, Truby L, Mundy L, Yang J, Kirtane AJ, Mongero L, Yuzefpolskaya M, Uriel N, Colombo PC, Jorde UP, Takeda K, Kodali SK, Naka Y, Takayama H. Partial Flow with 15F Arterial Cannula Provides Sufficient Circulatory Support in Veno-Arterial Extracorporeal Membrane Oxygenation. J Heart Lung Transplant 2014; 33 (4 Suppl): S250. 